\title{
Treponema pedis sp. nov., a spirochaete isolated from bovine digital dermatitis lesions
}

Correspondence

Nicholas J. Evans evansnj@liverpool.ac.uk

\author{
Nicholas J. Evans, ${ }^{1,2}$ Jennifer M. Brown, ${ }^{1}$ Ibrahim Demirkan, ${ }^{1} \dagger$ \\ Richard D. Murray, ${ }^{2}$ Richard J. Birtles, ${ }^{1}$ C. Anthony Hart ${ }^{3}$ \\ and Stuart D. Carter ${ }^{1,2}$
}
${ }^{1}$ Department of Veterinary Pathology, Faculty of Veterinary Science, University of Liverpool, Liverpool L69 3BX, UK
${ }^{2}$ Department of Veterinary Clinical Science, Faculty of Veterinary Science, University of Liverpool, Leahurst, Neston CH64 7TE, UK
${ }^{3}$ Department of Medical Microbiology, Genitourinary Medicine, Faculty of Medicine, Duncan Building, University of Liverpool, Liverpool L69 3GA, UK

\begin{abstract}
Bovine digital dermatitis (BDD) is a debilitating infection that is being increasingly recognized in livestock worldwide. Several treponeme phylotypes have been identified in BDD lesions, although only a single BDD-associated treponeme taxon (Treponema brennaborense) has been proposed thus far. In a previous study, we observed that four BDD-associated spirochaete isolates formed a distinct phylogenetic cluster on the basis of 16S rRNA gene sequence analysis and shared less than $97 \%$ sequence similarity with recognized treponeme species. Further characterization of these isolates on the basis of growth characteristics, flaB2 gene sequences, enzyme profiles and cell morphology confirmed that they formed a coherent taxonomic group displaying marked genotypic and phenotypic differences with respect to recognized treponeme species. The four novel isolates displayed a novel $3: 6: 3$ flagellar pattern rather than the $2: 4: 2$ pattern shown by their closest relatives and exhibited esterase $\mathrm{C} 4$, esterase lipase $\mathrm{C} 8$, trypsin and chymotrypsin enzyme activities. Therefore these four new isolates represent a novel species of the genus Treponema, for which the name Treponema pedis sp. nov. is proposed. The type strain is T3552B ${ }^{\top}\left(=\right.$ DSM $18691^{\top}=$ NCTC $\left.13403^{\top}\right)$.
\end{abstract}

Treponemes are typically found in the oral cavity, digestive tract and genital areas of humans and animals (Smibert, 1984). Several treponeme taxa are associated with disease and there is an unequivocal aetiology for certain treponeme infections such as human syphilis and yaws, which are caused by Treponema pallidum subsp. pallidum and T. pallidum subsp. pertenue, respectively (Radolf et al., 2006). In contrast, other treponeme infections, such as human periodontal infections and

†Present address: Department of Surgery, Faculty of Veterinary Medicine, Afyon Kocatepe University, 03200, Afyonkarahisar, Turkey.

Abbreviations: BDD, bovine digital dermatitis; FCS, fetal calf serum.

The GenBank/EMBL/DDBJ accession numbers for the 16S rRNA gene sequences of strains T3552B ${ }^{\mathrm{T}}, \mathrm{T} 18 \mathrm{~B}, \mathrm{~T} 354 \mathrm{~A}$ and G819CB are EF061268, EF061270, EF061267 and EF061269, respectively. The accession numbers for the flaB2 gene sequences of strains T3552B', T18B, T354A and G819CB are EF061284, EU754824, EF061283 and EU754823, respectively.

The growth characteristics of strain $\mathrm{T} 352 \mathrm{~B}^{\mathrm{T}}$ on FAA plates supplemented with defibrinated sheep blood and FCS are shown in a supplementary figure available with the online version of this paper. bovine digital dermatitis (BDD), appear to have a more complicated aetiology involving co-infection by several different treponemes (Choi et al., 1997; Dewhirst et al., 2000). Cloning and sequencing of 16S rRNA genes has been used to identify the presence of a diverse range of treponemes in polytreponemally infected tissue, but their highly fastidious nature has, for the most part, precluded any further characterization of these organisms. Although some progress has been made in elucidating the taxonomy of treponemes associated with human periodontal infections, only a single BDD-associated treponeme taxon, Treponema brennaborense (Schrank et al., 1999), has been proposed thus far. This is despite at least five treponeme phylotypes having been identified in BDD lesions (Choi et al., 1997) and several isolation reports of BDD treponemes that correspond to three of the five groups (Evans et al., 2008; Trott et al., 2003; Walker et al., 1995). Furthermore, T. brennaborense was not identified in any BDD lesions during a recent epidemiological study, suggesting that this species may not be as important in disease pathogenesis as initially perceived (Nordhoff et al., 2008). 
In a recent survey of spirochaetes present in BDD lesions in the UK, we obtained 23 isolates, which we delineated into three phylogroups on the basis of $16 \mathrm{~S}$ rRNA gene sequence comparisons (Evans et al., 2008). The 16S rRNA gene sequences of the three phylogroups clustered closely with three of the five spirochaetal phylogroup 16S rRNA gene fragments previously described as being present in BDD lesions and reported as being found within the genus Treponema (Choi et al., 1997). As the three phylogroups we isolated appeared to be genotypically and phenotypically distinctive and had been collected from a novel niche, we wanted to clarify their taxonomic status further. However, as two of these three phylogroups shared almost identical $16 \mathrm{~S}$ rRNA gene sequences with established species of the genus Treponema, namely Treponema medium and 'Treponema phagedenis', DNA-DNA hybridization and/or multilocus sequence-analysis studies were necessary for the precise determination of their taxonomic relationship with these species. The third phylogroup shared less than $97 \%$ $16 \mathrm{~S}$ rRNA gene sequence similarity with recognized Treponema species. In the present study, these data have been combined with novel genotypic and phenotypic characterizations to support the proposal of this phylogroup as a novel species of the genus Treponema.

The isolation of the BDD-associated spirochaetes studied here has been described previously (Evans et al., 2008). Biopsies were taken from BDD lesions in Holstein-Friesian cows in the UK. Four spirochaete strains $\left(\mathrm{T} 3552 \mathrm{~B}^{\mathrm{T}}, \mathrm{T} 354 \mathrm{~A}\right.$, G819CB and T18B) that comprised a distinct phylogroup (Evans et al., 2008) were isolated from different cows on different farms across the UK and were initially grown in oral treponeme enrichment broth (OTEB; Anaerobe Systems) supplemented with $10 \%(\mathrm{v} / \mathrm{v})$ fetal calf serum (FCS). Only poor growth was observed in the absence of FCS or if $10 \%(\mathrm{v} / \mathrm{v})$ rabbit serum was used as an alternative to FCS. This differed from the growth shown by the other two groups of BDD-associated spirochaetes isolated in the aforementioned study: T. medium-like isolates preferred to grow in rabbit serum and ' $T$. phagedenis'-like isolates required reinoculation every 7 days, as opposed to the 4 days required for the spirochaetes described in this work. The isolated treponemes could be stored at $-80{ }^{\circ} \mathrm{C}$ in growth medium containing $10 \%(\mathrm{v} / \mathrm{v})$ glycerol. Under phase-contrast microscopy, cells in liquid media could be identified as highly motile, showing both rotational and translational movement as well as jerky flexing. Spherical bodies could be observed in older cultures (from stationary phase onwards) and the spirochaete cells were typically found sedimenting towards the bottom of the tube.

The four spirochaete isolates were inoculated onto fastidious anaerobe agar (FAA) plates (LabM) supplemented with $5 \%(\mathrm{v} / \mathrm{v})$ defibrinated sheep blood and $10 \%(\mathrm{v} / \mathrm{v})$ FCS and incubated in an anaerobic cabinet $\left(\mathrm{N}_{2} / \mathrm{H}_{2} / \mathrm{CO}_{2}\right.$, $85: 10: 5,36{ }^{\circ} \mathrm{C}$, Fred Baker). All four isolates had the same growth characteristics; after 4 days incubation, the FAA plates yielded translucent, circular, convex single colonies $\sim 0.2 \mathrm{~mm}$ in diameter and the colonies achieved a final size of $\sim 0.5-2.0 \mathrm{~mm}$ after 11 days (see Supplementary Fig. S1a, available IJSEM Online). Distinct $\beta$-haemolysis appeared underneath some colonies after 3 weeks, whilst irregularly shaped projections with a characteristic metallic sheen had grown from many colonies (see Supplementary Figs S1b, c, available in IJSEM Online). Several of the $\beta$-haemolysis zones were penetrative, being visible from the underside of the plate. At 4 weeks, the novel protrusions had covered the entire plate, demonstrating the high degree of motility of these micro-organisms. Similar growth was observed on FAA plates containing $10 \%(\mathrm{v} / \mathrm{v})$ rabbit serum as an alternative serum supplement, whilst inoculation onto FAA plates not containing serum resulted in no subsequent growth, suggesting that these treponemes were serumdependent in vitro.

Genomic DNA preparation, subsequent PCR amplification of the 16S rRNA and flagellar subunit FlaB2 (flaB2) genes and sequencing of the amplification products for each of the four isolates were performed as described previously (Evans et al., 2008). For sequence comparison, approximately $1320 \mathrm{bp}$ of the $16 \mathrm{~S}$ rRNA gene sequences for each isolate were aligned against relevant recognized species of the genus Treponema by using CLUSTAL W (Thompson et al., 1994). The four isolates shared at least $99.7 \% 16 \mathrm{~S}$ rRNA gene sequence similarity with one another but showed less than $97 \%$ similarity with respect to all of the recognized species of the genus Treponema (96.6\% with Treponema putidum ATCC $700334^{\mathrm{T}}$ and $95.7 \%$ with Treponema denticola ATCC $35405^{\mathrm{T}}$ ) and only $86 \%$ with the previously described BDD treponeme, T. brennaborense DSM $12168^{\mathrm{T}}$. Phylogeny was inferred from this alignment by using the neighbour-joining method with nucleotide substitution rates calculated according to the Kimura two-parameter model implemented in MEGA2 (Kumar et al., 2001). The robustness of the proposed branching order was tested using bootstrapping (1000 iterations). Phylogenetic reconstruction (Fig. 1) revealed that the four isolates separated into a distinct and well-supported phylogroup that diverged from an ancestor of $T$. putidum/T. denticola before these two species diverged from one another. The evolutionary distance between the novel phylogroup and $T$. putidum or T. denticola was akin to that observed between sister species throughout the genus Treponema.

Sequences $(510 \mathrm{bp}$ ) for the flaB2 locus of the four isolates studied were obtained and compared with one another and with flaB2 sequences available for other species of the genus Treponema. The sequences of the four novel isolates $\left(\mathrm{T} 3552 \mathrm{~B}^{\mathrm{T}}, \mathrm{T} 354 \mathrm{~A}, \mathrm{G} 819 \mathrm{CB}\right.$ and $\left.\mathrm{T} 18 \mathrm{~B}\right)$ shared a minimum of $97.8 \%$ similarity with one another, but had less than $77 \%$ similarity with the flaB2 sequences of the type strains of other Treponema species. Phylogenetic analysis inferred from the alignment of flaB2 sequences indicated that strains $\mathrm{T} 3552 \mathrm{~B}^{\mathrm{T}}, \mathrm{T} 354 \mathrm{~A}, \mathrm{G} 819 \mathrm{CB}$ and $\mathrm{T} 18 \mathrm{~B}$ clustered together on a deep-rooted, well-supported branch within the evolutionary radius of the Treponema genus (Fig. 2). In agreement with analyses based on 16S rRNA gene sequences, flaB2-sequence-based analyses showed that the 


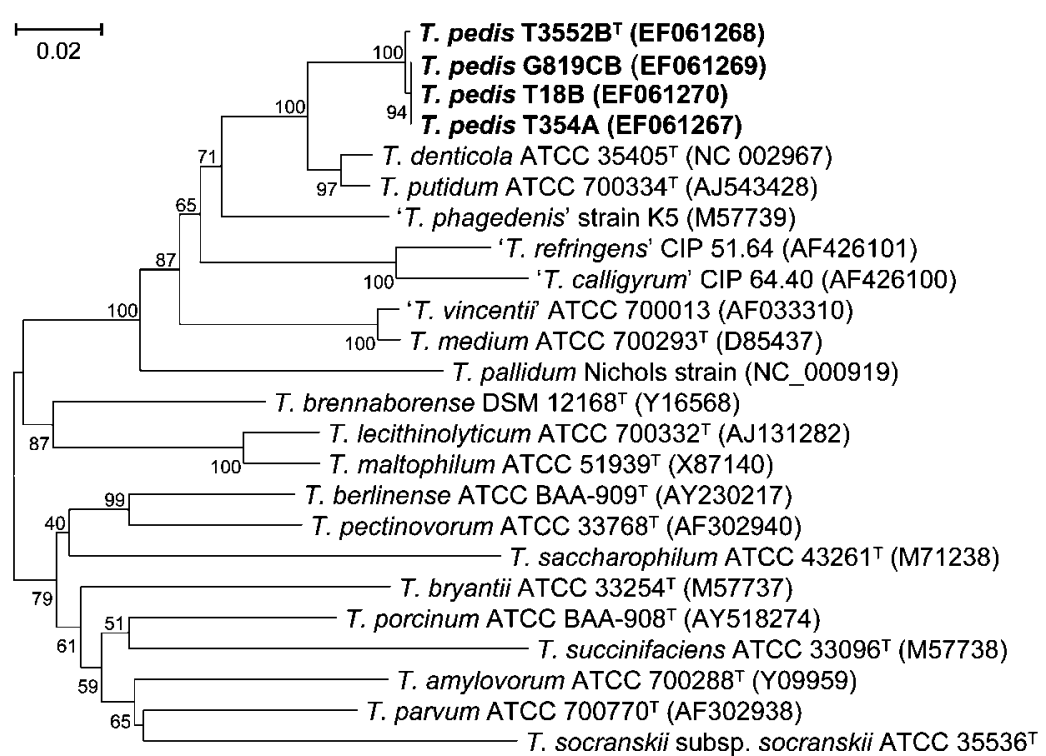

(AF033306)

\begin{abstract}
Fig. 1. Neighbour-joining phylogenetic tree, based on 16S rRNA gene sequence comparisons over $\sim 1320$ aligned bases, showing the relationships between the bovine spirochaete isolates (shown here in bold) and related species. Bootstrap percentages (based on 1000 iterations) are shown at the nodes; only values $>40 \%$ are shown. Accession numbers are shown in parentheses. Bar, 0.02 substitutions per site.
\end{abstract}

four novel isolates were specifically related to, but clearly distinct from, T. denticola.

The enzyme activities of each of the four novel isolates were determined using the API ZYM system (bioMérieux) according to the manufacturer's instructions, with each test being performed in triplicate. The patterns of reactivity were identical for the four isolates, with positive results for esterase C4, esterase lipase C8, trypsin and chymotrypsin activities. The enzyme profiles of the four isolates had a specific pattern (Table 1) that differed from that of recognized species of the genus Treponema. Complete enzyme profiles are listed in the species description.

The morphologies of the micro-organisms were examined using transmission electron microscopy as described previously (Demirkan et al., 2006) except that the spirochaetes were taken directly from liquid cultures. The four novel isolates shared common morphological characteristics: cells were 5-16 $\mu \mathrm{m}$ long and $0.2-0.3 \mu \mathrm{m}$ wide, had 4-10 windings and each possessed six periplasmic flagella (three originating at each end and overlapping in the central region of the cell) (Fig. 3). This novel $3: 6: 3$ flagellation pattern has been described previously as being a characteristic of Treponema amylovorum, a saccharolytic, medium-sized treponeme isolated from a periodontal lesion (Wyss et al., 1997); this species is genetically distant from the isolates under study, sharing less than $83 \% 16 \mathrm{~S}$ rRNA gene sequence similarity.

The results presented here clearly indicate that the four novel isolates form a coherent taxonomic group with almost-identical 16S rRNA gene sequences, very similar flaB2 gene sequences and identical enzyme activities, growth characteristics and cell morphology. Comparative $16 \mathrm{~S}$ rRNA and flaB2 gene sequence analysis clearly places these isolates within the genus Treponema, sharing ancestry with T. putidum and T. denticola. However, phylogenetic reconstructions indicate that the novel isolates form a specific evolutionary cluster that demonstrates marked divergence from these two recognized taxa. This divergence is reflected in phenotypic variation, as the novel isolates demonstrate a unique enzyme profile and an unusual $(3: 6: 3)$ flagellation pattern that differs from that of their

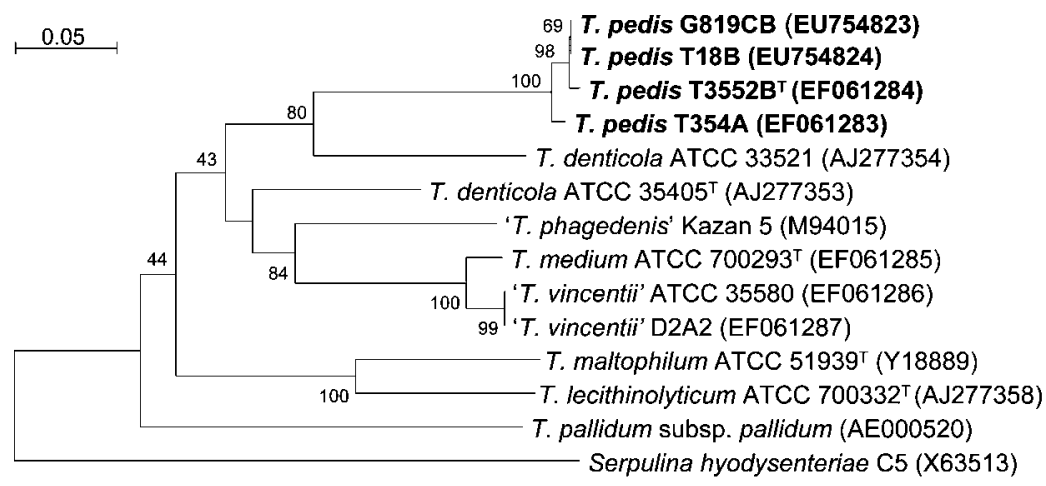

Fig. 2. Neighbour-joining phylogenetic tree based on flaB2 gene sequence comparison over 510 aligned bases, showing the relationships between the bovine spirochaete isolates (shown here in bold) and other reported flaB2 gene sequences. Accession numbers are shown in parentheses. Bootstrap percentages (based on 1000 iterations) are shown at the nodes; only values $>40 \%$ are shown. Bar, 0.05 substitutions per site. 
Table 1. Enzyme activities as determined using the API ZYM system

Strains: 1, T. brennaborense DSM $12168^{\mathrm{T}} ; 2$, T. amylovorum $\mathrm{HA}_{2} \mathrm{P}^{\mathrm{T}}$; 3, T. medium ATCC $700293^{\mathrm{T}}$; 4, 'T. vincentii ATCC 35580; 5, T. denticola ATCC $35405^{\mathrm{T}}$; 6, T. putidum ATCC $700334^{\mathrm{T}} ; 7$, T. pedis sp. nov. (data for strains T3552B ${ }^{\mathrm{T}}, \mathrm{T} 354 \mathrm{~A}, \mathrm{G} 819 \mathrm{CB}$ and T18B). Data for strains 1, 2 and 4 are from Schrank et al., 1999; data for strains 5 and 6 are from Wyss et al., 2004 and the remaining data are from this study. All strains give negative results for $\beta$-glucuronidase, $\alpha$-mannosidase, valine arylamidase, cystine arylamidase and lipase $\mathrm{C} 14 .+$, Positive; - , negative.

\begin{tabular}{|lccccccc|}
\hline Enzyme activities & $\mathbf{1}$ & $\mathbf{2}$ & $\mathbf{3}$ & $\mathbf{4}$ & $\mathbf{5}$ & $\mathbf{6}$ & $\mathbf{7}$ \\
\hline$N$-Acetyl- $\beta$-glucosaminidase & + & - & - & + & - & - & - \\
Acid phosphatase & + & + & - & + & - & + & - \\
Alkaline phosphatase & + & + & + & - & - & + & - \\
Chymotrypsin & - & - & - & - & + & + & + \\
Esterase C4 & + & + & + & - & + & + & + \\
Esterase lipase C8 & + & - & + & - & - & + & + \\
$\alpha$-Fucosidase & - & + & - & - & - & - & - \\
$\alpha$-Galactosidase & - & - & - & - & - & + & - \\
$\beta$-Galactosidase & + & - & + & + & - & + & - \\
$\alpha$-Glucosidase & + & - & - & - & - & + & - \\
$\beta$-Glucosidase & - & - & - & - & - & + & - \\
Leucine arylamidase & - & - & + & + & - & + & - \\
Naphthol phosphohydrolase & + & + & - & + & - & + & - \\
Trypsin & - & - & - & - & + & + & + \\
& & & & & & & \\
\hline
\end{tabular}

closest phylogenetic relatives, T. putidum and T. denticola (Wyss et al., 2004). Given the large number of similarities within the group and the differences that they exhibit with respect to recognized species of the genus Treponema, these four BDD-associated strains $\left(\mathrm{T} 3552 \mathrm{~B}^{\mathrm{T}}, \mathrm{T} 18 \mathrm{~B}, \mathrm{~T} 354 \mathrm{~A}\right.$ and G819CB) represent a novel species of the genus Treponema, for which the name Treponema pedis sp. nov. is proposed.

A fluorescence in situ hybridization study of smears from German BDD biopsies, analysed using a probe identical to a region of the $16 \mathrm{~S}$ rRNA gene of $T$. pedis sp. nov., implicated $T$. denticola-like spirochaetes as being most frequently present in this disease (Choi et al., 1997). Furthermore, Treponema sp. 1-9185MED, isolated from BDD lesions in the USA (Walker et al., 1995), shares 99.0\% 16S rRNA gene sequence similarity to the strains of T. pedis sp. nov. This possibly worldwide (UK, USA and Germany) presence of $T$. pedis sp. nov. suggests that this micro-organism might have a significant aetiological role in BDD. Further investigations are required to identify the pathogenic role that this novel species might have in BDD, while further taxonomic studies of BDD-associated spirochaetes are required to enable a better understanding of this significant disease.

\section{Description of Treponema pedis sp. nov.}

Treponema pedis ( $\mathrm{pe}^{\prime}$ dis. L. gen. n. pedis of the foot, referring to the source of isolation).

Gram-negative, anaerobic, motile, helically coiled, medium-sized treponemes. Cells are approximately 5-16 $\mu \mathrm{m}$ long and $0.2-0.3 \mu \mathrm{m}$ wide, with $4-10$ windings. Cells each have six periplasmic flagella: three originate at each cell end and overlap in the central region of the cell $(3: 6: 3$ flagellation pattern). Cells require 4 days anaerobic incubation at $36{ }^{\circ} \mathrm{C}$ to reach stationary phase in OTEB containing $10 \%(\mathrm{v} / \mathrm{v})$ FCS. In culture, cells exhibit rotational and translational movement as well as jerky flexing. When streaked on FAA plates containing $10 \%$ $(\mathrm{v} / \mathrm{v})$ FCS and $5 \%(\mathrm{v} / \mathrm{v})$ defibrinated sheep blood, colonies are $\sim 0.5-2.0 \mathrm{~mm}$ in diameter after 11 days. After 3 weeks incubation, distinct, penetrative $\beta$-haemolysis appears underneath colonies and irregularly shaped colonies with a metallic sheen grow from the original colonies. Growth is serum-dependent and optimal growth is achieved in OTEB using serum from a specific species (FCS). Cells can be stored at $-80{ }^{\circ} \mathrm{C}$ in growth medium supplemented with $10 \%(\mathrm{v} / \mathrm{v})$ glycerol. API ZYM analysis produces positive reactions for esterase $\mathrm{C} 4$, esterase lipase $\mathrm{C} 8$, trypsin and (a)

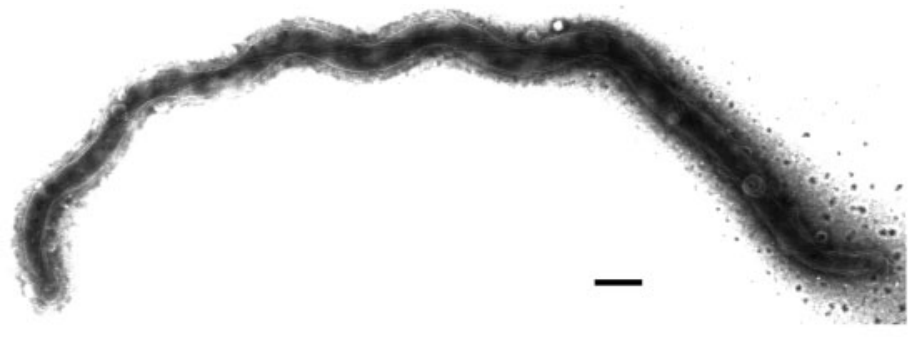

(b)

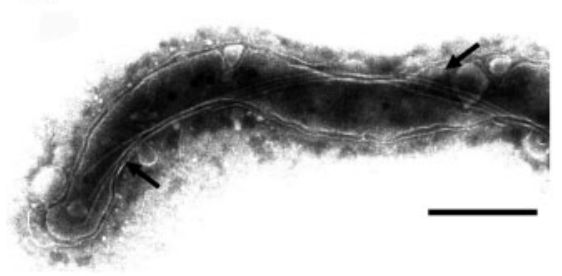

(c)

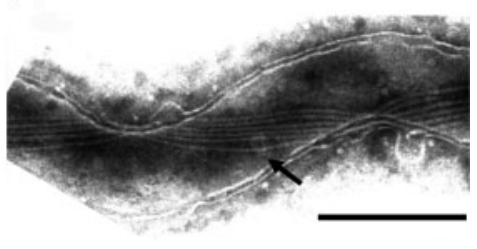

Fig. 3. Electron micrographs of negatively stained cells of the novel spirochaete strain T3552 $\mathrm{B}^{\top}$. The $3: 6: 3$ flagellar pattern is shown: (a) the whole cell; (b) one end of the cell, containing three flagella attached subterminally; (c) six overlapping flagella lying across the centre of the cell. Flagella are indicated by arrows. Bars, $0.5 \mu \mathrm{m}$. 
chymotrypsin and gives negative reactions for alkaline phosphatase, lipase C14, leucine arylamidase, valine arylamidase, cystine arylamidase, acid phosphatase, naphthol phosphohydrolase, $\alpha$-galactosidase, $\beta$-galactosidase, $\beta$-glucuronidase, $\alpha$-glucosidase, $\beta$-glucosidase, $N$-acetyl- $\beta$-glucosaminidase, $\alpha$-mannosidase and $\alpha$-fucosidase.

The type strain, T3552B ${ }^{\mathrm{T}}\left(=\mathrm{DSM} 18691^{\mathrm{T}}=\right.$ NCTC $\left.13403^{\mathrm{T}}\right)$, was isolated from a BDD lesion.

\section{Acknowledgements}

This work was funded by the UK Department for Environment, Food and Rural Affairs (animal welfare grant AW1010) and the UK Biotechnology and Biological Sciences Research Council (research grant BBE0189201).

\section{References}

Choi, B. K., Nattermann, H., Grund, S., Haider, W. \& Gobel, U. B. (1997). Spirochetes from digital dermatitis lesions in cattle are closely related to treponemes associated with human periodontitis. Int J Syst Bacteriol 47, 175-181.

Demirkan, I., Williams, H. F., Dhawi, A., Carter, S. D., Winstanley, C., Bruce, K. D. \& Hart, C. A. (2006). Characterization of a spirochaete isolated from a case of bovine digital dermatitis. J Appl Microbiol 101, 948-955.

Dewhirst, F. E., Tamer, M. A., Ericson, R. E., Lau, C. N., Levanos, V. A., Boches, S. K., Galvin, J. L. \& Paster, B. J. (2000). The diversity of periodontal spirochetes by $16 \mathrm{~S}$ rRNA analysis. Oral Microbiol Immunol 15, 196-202.

Evans, N. J., Brown, J., Demirkan, I., Murray, R. D., Vink, D., Blowey, R. W., Hart, C. A. \& Carter, S. D. (2008). Three unique groups of spirochetes isolated from digital dermatitis lesions in UK cattle. Vet Microbiol 130, 141-150.
Kumar, S., Tamura, K., Jakobsen, I. B. \& Nei, M. (2001). MEGA2: molecular evolutionary genetics analysis software. Bioinformatics 17, 1244-1245.

Nordhoff, M., Moter, A., Schrank, K. \& Wieler, L. H. (2008). High prevalence of treponemes in bovine digital dermatitis - a molecular epidemiology. Vet Microbiol 131, 293-300.

Radolf, J. D., Hazlett, K. R. O. \& Lukehart, S. A. (2006). Pathogenesis of syphilis. In Pathogenic Treponema: Molecular and Cellular Biology, pp. 197-236. Edited by J. D. Radolf \& S. A. Lukehart. Norfolk, UK: Caister Academic Press.

Schrank, K., Choi, B. K., Grund, S., Moter, A., Heuner, K., Nattermann, H. \& Gobel, U. B. (1999). Treponema brennaborense sp. nov., a novel spirochaete isolated from a dairy cow suffering from digital dermatitis. Int J Syst Bacteriol 49, 43-50.

Smibert, R. M. (1984). Genus III Treponema. In Bergey's Manual of Systematic Bacteriology, vol. 1, pp. 49-57. Edited by N. R. Krieg \& J. G. Holt. Baltimore: Williams and Wilkins.

Thompson, J. D., Higgins, D. G. \& Gibson, T. J. (1994). CLUSTAL W: improving the sensitivity of progressive multiple sequence alignment through sequence weighting, position-specific gap penalties and weight matrix choice. Nucleic Acids Res 22, 4673-4680.

Trott, D. J., Moeller, M. R., Zuerner, R. L., Goff, J. P., Waters, W. R., Alt, D. P., Walker, R. L. \& Wannemuehler, M. J. (2003). Characterization of Treponema phagedenis-like spirochetes isolated from papillomatous digital dermatitis lesions in dairy cattle. J Clin Microbiol 41, 2522-2529.

Walker, R. L., Read, D. H., Loretz, K. J. \& Nordhausen, R. W. (1995). Spirochetes isolated from dairy cattle with papillomatous digital dermatitis and interdigital dermatitis. Vet Microbiol 47, 343-355.

Wyss, C., Choi, B. K., Schüpbach, P., Guggenheim, B. \& Göbel, U. B. (1997). Treponema amylovorum sp. nov., a saccharolytic spirochete of medium size isolated from an advanced human periodontal lesion. Int J Syst Bacteriol 47, 842-845.

Wyss, C., Moter, A., Choi, B. K., Dewhirst, F. E., Xue, Y., Schüpbach, P., Göbel, U. B., Paster, B. J. \& Guggenheim, B. (2004). Treponema putidum sp. nov., a medium-sized proteolytic spirochaete isolated from lesions of human periodontitis and acute necrotizing ulcerative gingivitis. Int J Syst Evol Microbiol 54, 1117-1122. 